\title{
Peculiarities of the temperature mode of operation of asphalt in airfield coatings
}

\author{
A. Ramos $^{1}$, Eduard Kotlyarsky ${ }^{2 *}, Y$. Vasilev ${ }^{2}, V$. Talalay ${ }^{2}$ and $I$. Sarichev $^{2}$ \\ ${ }^{1}$ LLC "IPI" Technopark ", 125319, Moscow, Leningrad Prospect, 64, Russia \\ ${ }^{2}$ Moscow Road-Road State Technical University (MADI), 125319, Moscow, Leningrad Prospect, 64, \\ Russia
}

\begin{abstract}
The article makes an attempt to theoretically substantiate the need to take into account the increase in the temperature of the asphalt concrete aerodrome covering when the jet jets of aircraft aircraft are repeatedly exposed to the surface of the coating not only when calculating the thermodynamic stability of the upper layer at a jet velocity equal to or exceeding $100 \mathrm{~m} / \mathrm{s}$ but also for other operational conditions. This will reduce the risks of plastic deformation, likely jet erosion, potholes, even at the design stage and apply asphalt mixes with specified properties for the top coat.

Based on the laws of transfer of thermal energy, a theory was developed for calculating the temperature variation on the surface of the coating and the temperature distribution over the depth of the layer, from the effect of gas jets. The depth of heating by the gas jet of the upper asphaltconcrete layer and the factors determining this value are determined.

The theoretical dependences describing the change in the temperature of the surface of the coating from the action of gas jets and the propagation of temperature fields along the thickness of the structure are revealed. The results of calculations of the temperature of the upper asphalt-concrete layer of the coating under the action of gas jets and in their absence in various operational and climatic conditions are presented on the example of the Republic of Peru.
\end{abstract}

\section{Introduction}

One of the peculiarities of airfield coatings operation is the thermal and force impact of the reactive jets of the exhaust gases of the engines, which simultaneously with power loads from the mass of aircraft and natural-climatic factors are perceived by the surface of the coating and affect the formation of various defects and deformations.

Currently, asphalt is widely used in airfield coatings as a material for structural layers and reinforcement layers. It has high operational properties and manufacturability at construction and repair of coatings, but has a significant drawback-high dependence of physical and mechanical properties of a material, such as durability and deformability from temperature. Therefore for safety of flights and durability of operation of an airfield covering it is

\footnotetext{
Corresponding author: eco46@mail.ru
} 
necessary objective estimation of thermal mode of work of asphalt, taking into account all spectrum of temperature influences and specificity of operation of jet Aircraft.

Experience of aerodromes operation shows that at leakages of jet gas jets there is spasmodic short-term increase of the coating temperature. Depending on the size and duration of the temperature impact on the surface is burnout, and at a lower temperature or less duration of exposure-softening organic binder. In the first case, the non-associated bitumen mineral components asphalt under the influence of high-speed pressure jet blown from the coating-formed jet erosion (Fig. 1), in the second case structural links between components asphalt weakened, and under the influence of high-speed pressure also occurs partial blowing of mineral particles from the surface of the coating. In the future, inkjet erosion contributes to the formation of potholes. If adhesive connections in blacktop are strong enough, and withstand temperature and influence of high-speed gas stream, the integrity of a material of a layer remains. However in this case at systematic influence of a gas jet there is accelerated aging of organic binder determining change of physical and mechanical properties of asphalt and contributing to its destruction in time. In addition, when softening asphalt in the coating under the influence of gas jets with a high probability may be the appearance of plastic deformations in the form of ruts and shifts $[2,3,4]$.

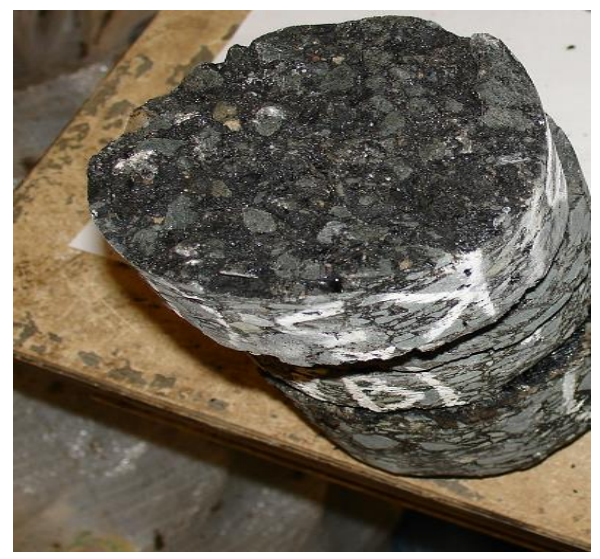

Fig. 1. Kern from the asphalt coating of the exposed jet erosion, selected from the site of the waiting area, combined with Rd. «Domodedovo Airport».

In addition, on coatings with asphalt layers, which have on the surface of various types of cracks, in the operation of wide aircraft with low-reactive engines may occur grad effect of the asphalt layer in the break-out on separate areas of airfield coverage.

One of the main reasons of destruction of asphalt coatings and layers of amplification at influence of gas jets of jet engines is imperfection of the design model and shortcomings at substantiation of requirements to the material-composition asphalt, and above all to the organic binder. This is facilitated by the lack of a comprehensive approach to assessing the temperature of the coating.

The purpose of our work is to develop a theoretically substantiated method of determining the calculated temperature of heating of asphalt coating taking into account all kinds of thermal impact on the surface of the coating including the jet exhaust of the aircraft.

This will allow with high accuracy to design airfield clothes and to select compositions of asphalt mixes for the top layers of coatings, thus, extending service life of a covering.

To achieve this goal the following tasks were solved:

1. Refinement of the mechanism of flow of jet spent gases of the aircraft to the surface of the airfield coating, factors influencing the formation of the field of the gas jet, character- 
istics of jet, including temperature and speed of movement the flow in its various points, as well as the fields of its distribution on the surface.

2. Clarification of the general regularities of heat exchange of the gas jet of the reactive engine with the surface of the airfield coating at the forced convection.

3. Development of theory of calculation of temperature of asphalt covering on a surface and distribution of temperature on depth of a layer at influence of a gas jet. Determination of the probable distance from the surface of the coating in the depth of the structure, on which there is an increase in temperature of the layer material.

4. Comparison of the surface temperature of the asphalt coating and its change on the depth of the airfield coating layer taking into account the impact of the jet and without it.

Considering the temperature problems applied to airfields it is necessary to note, characteristic only for airfield coverings temperature influence from gas jets of jet engines of aircrafts. This type of temperature influences has a number of specific features: they operate simultaneously with high-speed pressure and apply not on all coverages, but only on separate areas, such as starting areas of runways, pre-launch sites, parking places, waiting areas on taxiways tracks, waiting areas, engine testing sites, where the aircraft is at some time without traffic with running engines. When moving on the airfield of aircraft on its own thrust, the operating mode of motors $0,25 \mathrm{~N}$ due to short-term exposure and small speed, as a rule, there is no significant increase in surface temperature of the coating. Reliability and durability of the airfield complex, including safety of takeoff, landing, taxiing of modern aircraft in the conditions of probable inkjet erosion of coatings are largely determined by reliability and longevity of work individual elements of these coatings.

\section{Literature Review}

Currently, the assessment of the temperature regime of the coating, including at the aerodromes are dedicated to the work of many specialists. As a result, various empirical dependencies are established, adequately describing the processes in specific weather-climatic and geographical conditions, but without taking into account the thermal operational impacts.

Thermal and power effects of jet gas jets of aircraft, characteristics of temperature and speed fields arising at wraping jets of horizontal surfaces, including airfield coverings are described in works $[1,9,10]$, in mainly for hard coatings. The exception is the research V.E. Trigoni, etc. Leshhickoj for asphalt coatings [8.3] and works performed in FGUP GPI and NII GA "Aeroproject»" in the 1980s, which are now reflected in the "Design Guide Constructions of Airfield Coverings "-calculation on thermodynamic stability of the top layer at speed of jet stream exceeding $100 \mathrm{~m} / \mathrm{s}$, [2] and JV 121.13330.2012" airfields. Updated version of Snip 32-03-96 "[6].

From the conducted review of research works it follows that the interaction of gas jets of jet engines with asphalt coating and layers of amplification and determination of real temperature mode of operation of asphalt in the zone contact with the coated jet has been neglected for many years and the issue is not sufficiently developed.

\section{Materials and methods}

To solve the tasks of aerodrome maintenance of modern aircraft equipped with jet engines and increase the service life of airfield coatings and reinforcement layers, the calculation characteristics of reactive gas jets and the general patterns of heat transfer of a jet at forced convection. 
The expiration of the gas jet of the aircraft reactive engine on the surface of the airfield cover is at an angle of up to $6^{\circ}$ axisymmetric jet, spreading in a relatively stationary air, which is limited on the one hand surface of the airfield cover $[8,9]$.

At leakages on a covering the gas jet of a reactive engine spread on a surface of jelipsojdnoj form (Fig. 2), rendering thus thermal and force influence in a zone of contact to its surface. Thus there is a joint action of speed and temperature fields. Jet engine stream has a turbulent structure, which is characterized by speed, temperature, pressure and flux density. These factors experience chaotic oscillations, irregularly changing in space and time [1].

The maximum values of the temperature and velocity of the reactive gas jet is on its axis with a gradual decrease as it is removed from it to the borders of the gas flow.

Thermal and force impact of the gas jet avia on the airfield coverage today is estimated by the temperature and velocity of the jet at the point of touch with the surface [2.9], and there is no strict mathematical mechanism that allows virtually determine the temperature on the surface of the coating and spread it by the thickness of the structure layers.

In our work in the development of the theory of calculation of the change in the temperature of the coating from the effects of the jets of spent gases of reactive engines as the initial provisions were adopted general laws of heat exchange of gas jet of reactive the surface of the engine.

At wraping of a surface thermosetting a gas stream there is a heat transfer between hightemperature gas streams and a surface of a covering at the expense of forced convection [5.7].

The intensity of the heat transfer depends on: the temperature difference between the gas jet in its various points and the surface of the coating, the thermal properties of construction materials of airfield clothing, the condition of coverage and the duration of the process.

Since the thermal conductivity of the asphalt is relatively small, and the heat from the jet is short-term, the temperature gradients $\frac{d t}{d x}$ and $\frac{d t}{d y}$ in the directions of the parallel heating surface will be low compared to the temperature gradients $\frac{d t}{d z}$ of the layer thickness construction, in connection with this the equation of thermal conductivity was simplified and the problem of propagation of temperatures in half is reduced to the problem of propagation of heat in a semi-bounded body [9].

At creation of the theory of calculation of temperature of asphalt covering on a surface and distribution of temperature on depth of a layer at influence of a gas jet the temperature of heating of a surface of a covering at any point in zone the contact with the gas jet is determined from the condition of equal number of heat of $\mathrm{q}_{1}$, transmitted surface of the coating from the gas jet by forced convection during the engine operation, the number of heat $\mathrm{q}_{2}$ transferred from the surface of the coating in the depth of the structure layer in time. Since the heat from the jet is short-term, and the depth of warm-up of the top coat is small $(0.1 \ldots$. $3.0 \mathrm{~cm}$ ), it is possible to admit that $\mathrm{q}_{1}=\mathrm{q}_{2}$.

\section{Research results}

Using the laws of heat engineering and thermodynamics, we received a mathematical description of the thermal interaction of the gas jet with asphalt airfield coating.

$$
q_{1}=\alpha_{c} \cdot F \cdot\left(T_{\mathrm{c}}-T_{\text {п }}\right) \cdot \tau
$$




$$
q_{2}=2 \tau\left(T_{w}-T_{z}\right) \sqrt{\frac{\lambda_{n} \rho_{n} c_{n}}{\pi \tau}}
$$

$\mathrm{T}_{\Pi}$ - surface temperature of the coating to the impact of jet;

$\mathrm{T}_{\mathrm{c}}$ - the temperature of the jet at the point in the contact area of the coating;

$\tau$ - jet exposure time;

F - heated surface area;

$\mathrm{T}_{\mathrm{w}}$ - surface temperature of the coating when exposed to a gas jet;

$T_{Z}$ - the coating temperature at the bottom of the layer before the impact of the jet;

$\sqrt{\frac{\lambda_{n} \rho_{n} c_{n}}{\pi \tau}}$ - coefficient of absorption of the coating layer;

$\lambda_{\mathrm{I}}$ - asphalt thermal conductivity coefficient;

$\rho_{\text {пा }}$ - asphalt density;

$\mathrm{c}_{\mathrm{n}}$ - asphalt heat capacity;

$\alpha_{c}$ - convective coefficient of gas jet.

As a result of the solution of the equation system $\mathrm{q}_{1}$ and $\mathrm{q}_{2}$ was obtained dependence on the determination of temperature on the surface of the coating $T_{w}$. The heat from the surface of the coating spreads through the depth of the structure through heat transfer taking into account the thermal conductivity of the material. When calculating the temperature in the upper asphalt layer of the airfield coating, the latter can be considered as a semibounded body solid with boundary conditions of the 1st genus. Therefore, the distribution of temperature on the depth of the layer from the action of gas jets engines using the Gauss integral can be described by the following formula:

$$
T_{w}(z, \tau)=T_{0.0 n}+\left(1-\operatorname{erf} \frac{z}{2 \sqrt{\alpha \tau}}\right) *\left(T_{w}-T_{0,0 n}\right)
$$

$\mathrm{z}$ - coating thickness coordinate;

$\alpha$ - diffusivity coefficient of coating layer material;

$\tau$ - warm-up time;

$T_{0,0 n}$ - temperature at the lower edge of the layer in the absence of gas jet exposure;

$T_{w}$ - surface temperature of the coating when exposed to a gas jet.

In accordance with the developed method we have made calculations on the determination of the temperature of the asphalt layer of coverage during the operation of the aircraft type A-320: with different duration of the impact of gas jets on the coating, with different operating modes of the engine and at different ambient temperatures.

The work was carried out with the participation of the center for collective use MADI (CKP MADI). 
In fig. 2 there is a dependence of temperature distribution on a surface and on depth of a asphalt layer without consideration of thermal influence of gas jets and at work avia for 3 minutes in two different modes.

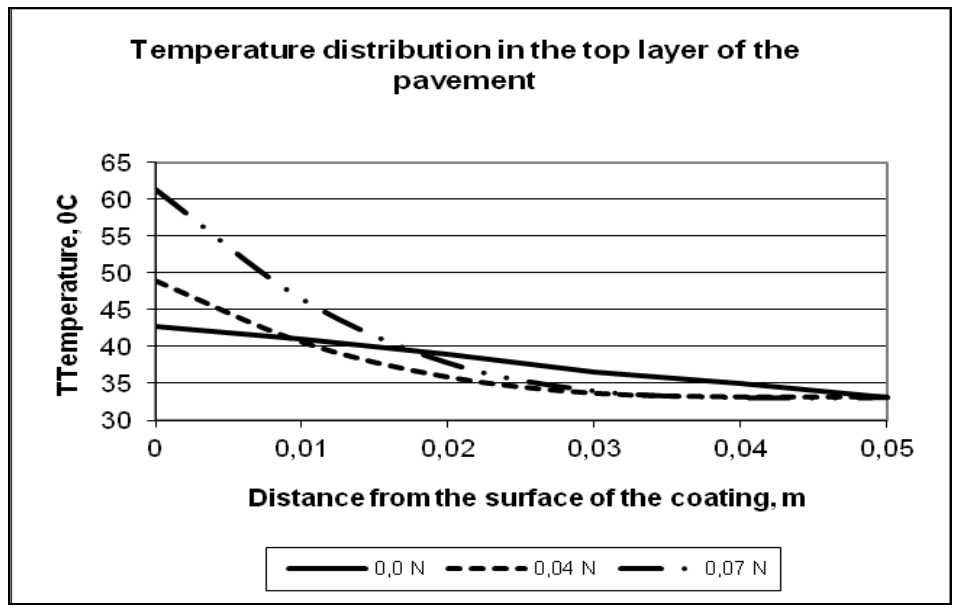

Fig. 2. Temperature on the surface of the coating and its distribution in the depth of the upper asphalt layer without the impact of jet gas jets and their impact within 3 minutes, when the engine of the aircraft type A-320 in the mode $0,7 \mathrm{~N}$ and $0,4 \mathrm{~N}$ at the same air temperature in the maximum exposure zone of the jet to the coating.

According to our calculations spasmodic increase of surface temperature of asphalt coating at leakages gas jet can reach $30^{\circ} \mathrm{C}$ and more. In the work all calculations were carried out for the aircraft of type A-320 climatic and operational conditions of the republic of Peru [12.13], therefore only positive ambient temperatures were considered.

\section{Conclusions}

Our researches, the developed method, the received mathematical dependencies and the executed calculations have allowed to define temperature of heating of a surface in the top asphalt layer of an airfield covering at influence of reactive gas jets. It is found that it differs significantly from the temperature of coverage under the influence of natural factors. An objective assessment of the thermal operation of the upper asphalt coating layer, which satisfactorily coincides with the natural experiment, was made. The practice of aerodrome operation testifies that the occurrence of deformations and destruction of coatings in most cases occurs not only because of exceeding of calculated power loads, and also because of incorrect estimation of real operating conditions coatings. This, first of all, refers to asphalt coatings and reinforcement layers. It is considered that the currently applied asphalt mixtures are characterized by low thermal resistance of binder and relatively weak adhesion between mineral particles and therefore can withstand only short-term effects hightemperature gas jets. In our opinion, one of the reasons is that the choice of the brand of organic binder for airfield asphalt mixes does not take into account the spasmodic increase in the temperature of coverage from the impact of gas jets.

Our work can be of interest to designers and builders of aerodrome complexes, as well as specialists engaged in the development of regulatory requirements for construction materials. 


\section{Reference}

1. Abramovich G.N. Theory of turbulent jets // Fizmatgiz. 2011. 715 p.

2. Guide to design of airfield cover designs. Step 2 // FGUP GPI and NII GA "Aeroproject» "Ajeroproet. 2004. P.113-120.

3. Leshickaja T. P. Dissertation on the topic: Increase of heat resistance of asphalt airfield coatings // Madi.1978. 143 p.

4. Leshickaja T.P., Popov V.A. Modern methods of repair of airfield coatings // Madi.1999. 131 p.

5. Lukanin V.N., Shatrov M.G., etc. Heat engineering // High School. 2009, 671 p.

6. SP 121.13330. Airfields // The Ministry of Regional Development. 2012. P. 63-59.

7. Shatrov M.G., Ivanov I.E., Prishvin S.A. Heat engineering // Ed. Center Academia. 2012, P. 287.

8. Trigoni V.E., Leshhickaja T.P., Yurchenko A.I. Increase of durability of asphalt layers of amplification at reconstruction of airfields // Madi 1998. $46 \mathrm{p}$.

9. Trigoni V.E. Jet erosion of airfields // Transport. 1981. 248 p.

10. Trigoni V.E. The effect of jet aircraft engines in the design of airfields// FGUP GPI and NII GA "Aeroproject» 1973. 48 p.

11. Goretski L.I. Theory and calculation of cement coatings on temperature effects // Transport.1965. $284 \mathrm{p}$.

12. Escalante Zegarra J. R. Clasificacion de ligantes asfalticos por desempeno para las diferentes regiones climaticas del Peru.// Construyendo Camino Revista Especializada en Ingenieria de Pavimentos Edicion- Lima. 2012. No. 5. P. 32-36.

13. Atlas de energia solar del Peru // Senamhi Lima-Peru. 2003. 78 p. 